\title{
Human skin keratins are the major proteins in exhaled breath condensate
}

\author{
H.J. Hoffmann*, L.M. Tabaksblat*, J.J. Enghild ${ }^{\#}$ and R. Dahl*
}

ABSTRACT: Exhaled breath condensate (EBC) may be an attractive noninvasive alternative to bronchoscopy, bronchoalveolar lavage and induced sputum for diagnosis and monitoring of pulmonary disease. The aim of the present study was to identify proteins in EBC by mass spectrometry. Protein in EBC was characterised by gel electrophoresis of freeze-dried EBC samples, and individual proteins were identified by mass spectrometry.

Saliva, ambient air condensate (AAC) and EBC were collected from normal human volunteers with or without a filter to remove particles from air. In some instances, EBC was condensed by breathing compressed air. Samples were freeze-dried and analysed by SDS-PAGE and peptide mass fingerprinting.

Three major bands were seen in EBC and AAC, and were identified by peptide mass fingerprinting. The probability-based Mowse score was significant only for cytokeratin (CK) 1, CK2 and CK10. In the catalogue of human cytokeratins, CK1, CK2, CK9 and CK10 are described in keratinising epidermis. Saliva did not contain keratin and compressed air EBC contained markedly less keratin. Filtration of inspired air did not remove contaminating keratin.

In conclusion, skin keratin in exhaled breath condensate derives from ambient air and not from the respiratory tract.

KEYWORDS: Airway inflammation, biomarkers, exhaled breath condensate, mass spectrometry

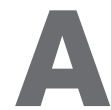
nalysis of proteins, in particular cytokines, from the lung can have diagnostic value and aid in classification of disease severity and activity [1]. Exhaled breath condensate (EBC), which has been the subject of a recent American Thoracic Society/European Respiratory Society Task Force [2], is obtained by collecting condensed liquid from exhaled breath in a cold trap. One advantage of this gentle sampling procedure would be significant relief for the patient. It can be used repeatedly on the same patient in outpatient settings to aid in the diagnosis of inflammatory [1], infectious [3] and neoplastic [4] disease.

Interleukin-6 in EBC has been measured by ELISA as a strong indicator of inflammatory responses [5-9], with a detection range of $0-$ $3 \mathrm{pg} \cdot \mathrm{mL}^{-1}$. An alternative method is identification using a protein gel, and confirmation of the primary sequence by peptide mass fingerprinting. Keratins CK1, CK2, CK9 and CK10 (with molecular weights of $67,65,64$ and $56.5 \mathrm{kDa}$, respectively $[10,11])$ are frequent contaminants of protein identification work [12]. CK1 and CK10 are restricted to the epidermis and epithelia undergoing skin-type differentiation to develop the stratum corneum [10, 13] and are continuously shed into the environment $[10,14]$. They are not expressed in the lung [15]. CK7, CK8, CK18 and CK19 are expressed in the alveolae, and CK5/6, CK14 and CK17 are expressed in the bronchii [11, 15]. Protein from EBC has only rarely been characterised [16]. The current authors attempted to discover lungderived protein by gel electrophoresis of freezedried EBC samples, and to identify the proteins by peptide mass fingerprinting.

\section{METHODS}

EBC samples were collected with a Jaeger Ecoscreen (Viasys HealthCare, Conshohocken, PA, USA) for 30 min from six healthy nonsmoking hospital workers (two males, four females, aged 28-55 yrs) breathing ambient air (EBC) or compressed air from the hospital supply (EBCC), and from ambient air condensate (AAC) samples. The project was registered with the local ethics committee. In some experiments a bacterial/viral filter (Vitalograph, Buckingham, UK) with a $99.99 \%$ reduction of load of particles $>10^{-6} \mathrm{~m}$ or a UFTD filter (Donaldson, Leuven, Belgium) with an absolute retention of particles $>2 \cdot 10^{-6} \mathrm{~m}$ were inserted before the air inlet. When compressed air was inhaled to generate EBCC, a valve was
AFFILIATIONS

*Dept of Respiratory Diseases, Aarhus University Hospital and \#Dept of Molecular Biology, University of Aarhus, Aarhus, Denmark.

CORRESPONDENCE

H.J. Hoffmann

Dept of Respiratory Diseases

Aarhus University Hospital

Building $2 b$

Nørrebrogade 44

DK 8000 Aarhus C

Denmark

Fax: 4589492110

E-mail: hans.jurgen.hoffmann@

ki.au.dk

Received:

May 162007

Accepted after revision:

October 142007

SUPPORT STATEMENT

Financial support was gratefully received from the Danish National Research Foundation and Aarhus Universities Research foundation.

STATEMENT OF INTEREST

None declared. 
inserted before the Ecoscreen to allow excess air to escape into the environment during tidal breathing.

Equivalent samples $(2 \pm 0.2 \mathrm{~mL})$ were freeze dried in a Speed vac apparatus (Savant SVC100, Instruments Inc., Farmingdale, NY, USA), and analysed by SDS-PAGE [17-19]. Stained bands were cut out of the gel, digested with trypsin, desalted by $\mathrm{C} 18$ ZipTip (Millipore, Copenhagen, Denmark) and eluted directly onto the sample plate of the mass spectrometer using $\alpha$-cyano4-hydroxycinnamic acid $\left(4 \mathrm{mg} \cdot \mathrm{mL}^{-1}\right.$ in $70 \%$ acetonitrile $/ 0.1 \%$ TFA). The samples were subsequently analysed by matrixassisted laser desorption ionisation time-of-flight mass spectrometry (MALDI-TOF MS) using a Q-Tof Ultima Global mass spectrometer (Micromass/Waters Corp., Manchester, UK). The instrument was calibrated over the mass-to-charge ratio $(\mathrm{m} / \mathrm{z})$ range 50-3000 using a polyethylene glycol mixture and glufibrinopeptide B (molecular weight $1570.677 \mathrm{kDa}$; Sigma, Brøndby, Denmark) as lock mass. Reflector mode was activated, and all samples were analysed in positive polarity mode. Laser shots $(10 \mathrm{~Hz})$ were accumulated until a satisfactory signal-to-noise ratio was achieved when combined and smoothed. The collision energy during tandem mass spectrometry experiments was $50-120 \mathrm{eV}$, and argon was used as collision gas. The mass accuracy was generally $<30 \mathrm{ppm}$ for all MS analyses. Mass spectra were acquired in the positive-ion mode over the range $800-3000 \mathrm{~m} / \mathrm{z}$. The determined mass of the peptides was used to query SwissProt/TrEMBL [20] or NCBInr protein databases using the Mascot search engine (Matrix Sciences, London, UK) [21]. The searches were performed with a peptide mass tolerance of 50 ppm, carbamidomethyl modification of cysteine residues and allowing a single missed tryptic cleavage. Only significant hits as defined by Mascot probability analysis and with at least five matches of peptide masses were accepted. The acquired MALDI-Q-TOF data were viewed in MassLynx Version 4.0 (Micromass/ Waters Corp.) and sequence handling for mass spectrometric data was carried out using the GPMAW software (Lighthouse Data, Odense, Denmark) [22].

\section{RESULTS}

A representative gel is shown in figure 1 (EBC-labelled lanes). The bands with a molecular weight of $66 \mathrm{kDa}$ contained CK1 and $\mathrm{CK} 2$, and bands of $55 \mathrm{kDa}$ molecular weight contained CK10. The band at $6-14 \mathrm{kDa}$ contained a fragment of CK2. Proteins of possible pulmonary origin for which peptides were detected are shown in table 1 . To exclude saliva as a source of keratin, saliva was analysed on SDS gels (fig. 1c). Major bands with a similar molecular weight to the bands identified in EBC contained lytic enzymes $\alpha$-amylase and lysozyme, determined by mass
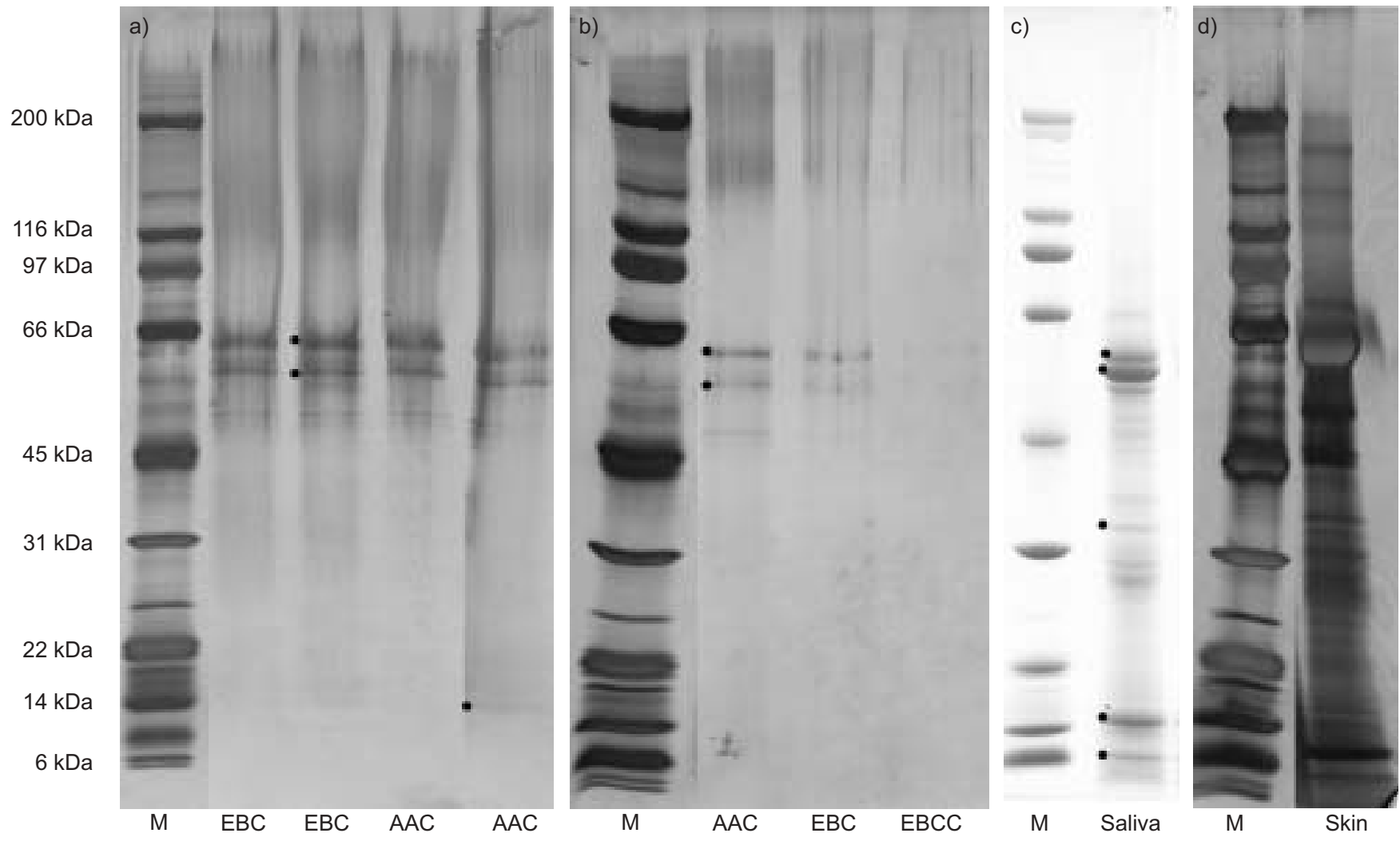

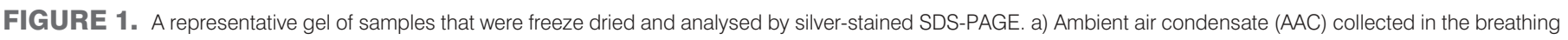

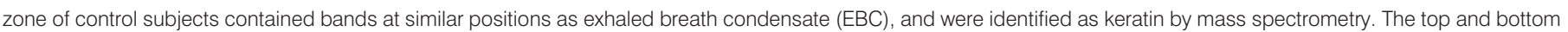

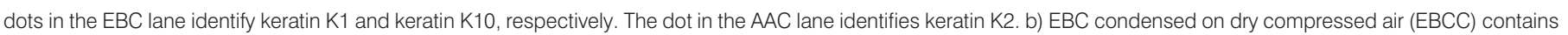

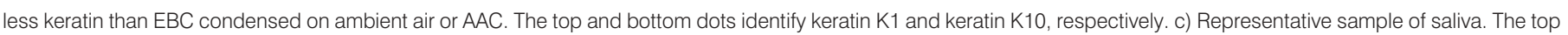

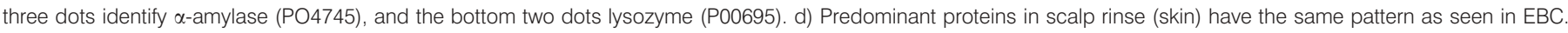
M: markers.

: bands sequenced by mass spectrometry. 


\begin{tabular}{ll} 
TABLE 1 & $\begin{array}{l}\text { Peptides of pulmonary origin detected with } \\
\text { cytokeratin (CK) 1,2 and } 10 \text { in exhaled breath } \\
\text { condensate (EBC) }\end{array}$ \\
& Peptides n \\
\hline Sample A & \\
CK1 and CK2 & 10 \\
P48669 CK6 & 13 \\
P05787 CK8 & 11 \\
Sample B & \\
CK10 & 6 \\
P48669 CK6 & 5 \\
P19013 CK4 & 4 \\
Sample C & \\
CK1 and CK2 & 11 \\
CK9 & 6 \\
CK10 & 8 \\
CK4 & 4 \\
CK6 & 7 \\
P35247 pulmonary surfactant associated & 4 \\
protein & \\
\hline
\end{tabular}

Samples A and B correspond to figure 1a, top and bottom EBC lanes, respectively. Sample $C$ corresponds to the ambient air condensate (AAC) lane in figure 1a. ${ }^{*}$ : in each case, only keratin had a probability-based Mowse score of significance.

spectrometry. No keratin peptides were identified in saliva, and neither $\alpha$-amylase nor lysozyme were detected in EBC.

To identify proteins present at levels not detectable by silverstained SDS-PAGE, an aliquot of EBC was freeze dried, and separated on a size exclusion column into fractions larger and smaller than $30 \mathrm{kDa}$. Both fractions were analysed by mass spectrometry. No peptides were identified in the low molecular weight fraction, whereas keratins $\mathrm{K} 1$ and $\mathrm{K} 10$ were again identified in the high molecular weight fraction (not shown).

As the keratin in EBC was not of the type normally associated with the lung and was not found in saliva, a possible source outside the lung was investigated. Water-soluble protein in a scalp rinse of one participant contained a similar protein pattern as EBC with major bands between $50-66 \mathrm{kDa}$, and a minor band at 6-14 kDa (fig. 1d).

To show that the keratin in EBC stems from ambient air, a weak vacuum source was attached to the EcoScreen to draw ambient air from the breathing region of a test subject through the cold trap without drawing it into a human lung first. The volume of condensate collected from ambient air $(3.29 \pm 1.43 \mathrm{~mL})$ was less than EBC collected over the same time $(7.58 \pm 1.70 \mathrm{~mL})$. It was concentrated and analysed similarly to EBC, and contained CK1 and CK2 (fig. 1a).

As the keratin in EBC appeared to derive from ambient air, a Vitalograph filter or a UFTD filter was placed in line in front the Ecoscreen air intake to remove debris from ambient air. The filters did not remove appreciable amounts of protein from EBC or AAC (not shown).

As ambient air contains the contaminating keratins, EBC was condensed from subjects breathing compressed air from the hospitals air supply. This substantially reduced the amount of keratin in the EBC samples (fig. 1b). No liquid could be condensed from compressed air even when the collection time was extended to $2 \mathrm{~h}$, probably because there was no moisture in the compressed dry air. EBC condensed on compressed air had a volume $(6.72 \pm 1.66 \mathrm{~mL})$ similar to that condensed on ambient air.

\section{DISCUSSION}

In attempts to identify novel proteins in EBC by gel electrophoresis, the current authors have only succeeded in finding skin keratin, in all likelihood debris from human stratum corneum in ambient air (table 2). Keratin, shed continuously from skin, is a ubiquitous contaminant in protein identification work [12]. To the present authors' knowledge, this is the fourth publication $[16,24,25]$ to document that keratin is a major constituent of proteins found in EBC, and the first to consider that the keratin found stems from the skin, as it is not expressed in the lung. As the keratin load could not be reduced by filters shown to remove viruses and bacteria, the keratin-containing debris must be smaller. It is also the first time that a reduction of keratin content is documented when the air inhaled for generation of EBC is not ambient air, but

TABLE 2 Expression of keratin types in the lung and skin

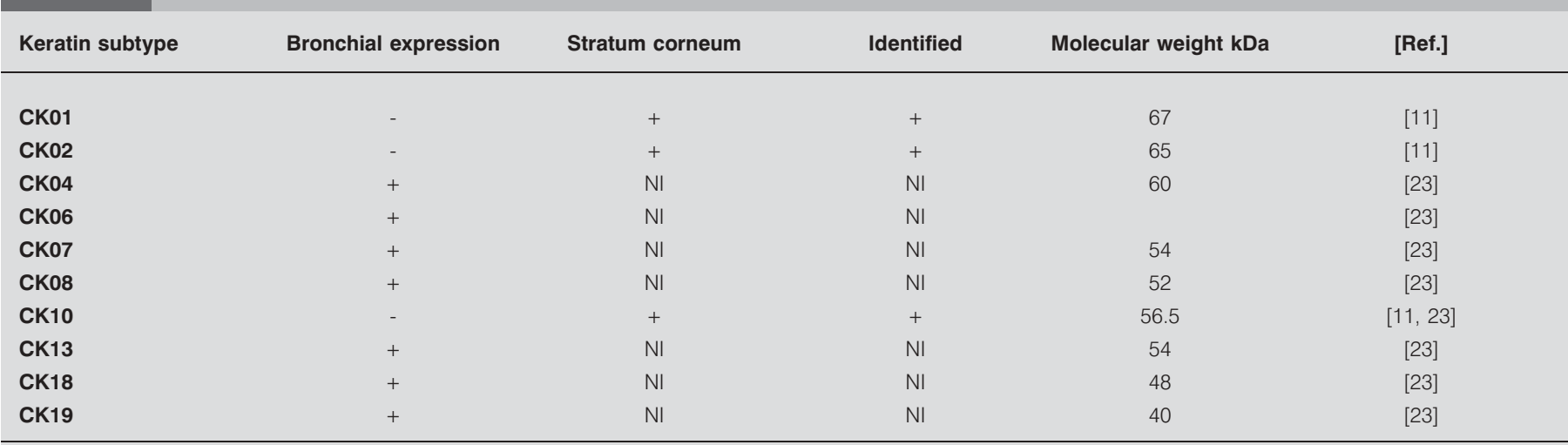

CK: cytokeratins; NI: not investigated. +: presence of protein investigated; -: absence of protein investigated 
compressed air that may contain less keratin. The volume of EBC condensed on compressed air was only marginally less that that condensed on ambient air, illustrating that inspired air is humidified to a uniform degree by the airways.

The protein bands at 67, 65 and $56.5 \mathrm{kDa}$ containing CK1 and CK2, and CK10, respectively, constitute full-length keratin. The variable bands $<20 \mathrm{kDa}$ may represent degradation products. Peptides from a number of other proteins, including keratins, were detected in EBC (table 1), but the software for assigning the identity to the bands determined that the most likely candidates were CK1, CK2 and CK10 [10]. Although peptides of proteins of pulmonary origin were detected, the probability-based Mowse score was only significant for keratins K1, K2 and K10.

The current data suggest that most protein in EBC is in fact molecular debris shed from the stratum corneum inhaled with inspired air. As the inspired air is humidified, the relatively cold keratin molecules could act as foci around which water molecules condense. Lysozyme and $\alpha$-amylase were detected in saliva samples but not in EBC, confirming that there is no salivary contamination when collecting EBC with an Ecoscreen. The present study was performed in healthy subjects. Similar studies in patients with well-characterised lung disease should be performed.

Bronchoalveolar lavage and EBC keratin content is similar by weight [25]. EBC of smokers contained elevated amounts of CK9 and CK10 [24]. The skin of smokers tends to age and turnover more rapidly than that of nonsmokers, hence smokers will have more skin debris in their ambient air.

The current authors did not find any cytokines in exhaled breath condensate. Peptide mass fingerprinting may not be sensitive enough, as the limit of detection is set by visualisation of protein bands on SDS-PAGE, which is at best $140 \mathrm{pg} \cdot \mathrm{mL}^{-1}$ (1 ng in $7 \mathrm{~mL}$ of exhaled breath condensate) [19]. The limit of detection of the ELISA for human interleukin-6 supplied by Cayman Chemical (Tallinn, Estonia), which has most often been used in analysis of exhaled breath condensate, is $1.5 \mathrm{pg} \cdot \mathrm{mL}^{-1}$, which is 100 times more sensitive. The concentration of interleukin- 6 in exhaled breath condensate is reported to be $<3 \mathrm{pg} \cdot \mathrm{mL}^{-1}$ [5-9]. Therefore, $120-700 \mathrm{~mL}$ of exhaled breath condensate would be needed to visualise interleukin-6 in exhaled breath condensate on a gel for peptide mass fingerprinting. Cytokines have only been documented by ELISA and, as the major weight fraction of protein in exhaled breath condensate derives from ambient air, it becomes important to determine whether cytokines measured in EBC derive from the lung or whether they, like keratin, are debris from ambient air.

\section{ACKNOWLEDGEMENTS}

I.B. Thøgersen (Dept of Molecular Biology, University of Aarhus, Aarhus, Denmark) provided excellent technical assistance and D. Knudsen (IDWorks, Aarhus, Denmark) for assistance with figure 1.

\section{REFERENCES}

1 Montuschi P. New Perspectives in Monitoring Lung Inflammation: Analysis of Exhaled Breath Condensate. Boca Raton, CRC Press, 2004.
2 Horváth I, Hunt J, Barnes PJ, et al. Exhaled breath condensate: methodological recommendations and unresolved questions. Eur Respir J 2005; 26: 523-548.

3 Majewska E, Kasielski M, Luczynski R, Bartosz G, Bialasiewicz P, Nowak D. Elevated exhalation of hydrogen peroxide and thiobarbituric acid reactive substances in patients with community acquired pneumonia. Respir Med 2004; 98: 669-676.

4 Gessner C, Kuhn H, Toepfer K, Hammerschmidt S, Schauer J, Wirtz H. Detection of p53 gene mutations in exhaled breath condensate of non-small cell lung cancer patients. Lung Cancer 2004; 43: 215-222.

5 Rosias PPR, Dompeling E, Dentener MA, et al. Childhood asthma: exhaled markers of airway inflammation, asthma control score, and lung function tests. Pediatr Pulmonol 2004; 38: 107-114.

6 Qiao H, Wang Gf, Zhang H, Ding CM. [The interleukin-6 level in exhaled breath condensate of patients with obstructive sleep apnea-hypopnea syndrome.] Zhonghua Jie He He Hu Xi Za Zhi 2005; 28: 364-367.

7 Gessner C, Scheibe R, Wötzel M, et al. Exhaled breath condensate cytokine patterns in chronic obstructive pulmonary disease. Respir Med 2005; 99: 1229-1240.

8 Carpagnano GE, Foschino Barbaro MP, Cagnazzo M, et al. Use of exhaled breath condensate in the study of airway inflammation after hypertonic saline solution challenge. Chest 2005; 128: 3159-3166.

9 Sack U, Scheibe R, Wötzel M, et al. Multiplex analysis of cytokines in exhaled breath condensate. Cytometry A 2006; 69: 169-172.

10 Eichner R, Kahn M. Differential extraction of keratin subunits and filaments from normal human epidermis. $J$ Cell Biol 1990; 110: 1149-1168.

11 Pendleton N, Dixon GR, Green JA, Myskow MW. Expression of markers of differentiation in normal bronchial epithelium and bronchial dysplasia. J Pathol 1996; 178: 146-150.

12 Ding Q, Xiao L, Xiong S, et al. Unmatched masses in peptide mass fingerprints caused by cross-contamination: an updated statistical result. Proteomics 2003; 3: 1313-1317.

13 Tseng SC, Jarvinen MJ, Nelson WG, Huang JW, WoodcockMitchell J, Sun TT. Correlation of specific keratins with different types of epithelial differentiation: monoclonal antibody studies. Cell 1982; 30: 361-372.

14 Bowden PE, Quinlan RA, Breitkreutz D, Fusenig NE. Proteolytic modification of acidic and basic keratins during terminal differentiation of mouse and human epidermis. Eur J Biochem 1984; 142: 29-36.

15 Blobel GA, Moll R, Franke WW, Vogt-Moykopf I. Cytokeratins in normal lung and lung carcinomas. I. Adenocarcinomas, squamous cell carcinomas and cultured cell lines. Virchows Arch B Cell Pathol Incl Mol Pathol 1984; 45: 407-429.

16 Scheideler L, Manke HG, Schwulera U, Inacker O, Hammerle H. Detection of nonvolatile macromolecules in breath. A possible diagnostic tool? Am Rev Respir Dis 1993; 148: 778-784.

17 Bury AF. Analysis of protein and peptide mixtures. Evaluation of three sodium dodecyl sulfate-polyacrylamide gel electrophoresis buffer systems. J Chromatogr 1981; 213: 491-500. 
18 Shevchenko A, Wilm M, Vorm O, Mann M. Mass spectrometric sequencing of proteins silver-stained polyacrylamide gels. Anal Chem 1996; 68: 850-858.

19 Sørensen BK, Højrup P, Østergård E, et al. Silver staining of proteins on electroblotting membranes and intensification of silver staining of proteins separated by polyacrylamide gel electrophoresis. Anal Biochem 2002; 304: 33-41.

20 Boeckmann B, Bairoch A, Apweiler R, et al. The SWISSPROT protein knowledgebase and its supplement TrEMBL in 2003. Nucleic Acids Res 2003; 31: 365-370.

21 Perkins DN, Pappin DJ, Creasy DM, Cottrell JS. Probability-based protein identification by searching sequence databases using mass spectrometry data. Electrophoresis 1999; 20: 3551-3567.
22 Peri S, Steen H, Pandey A. GPMAW-a software tool for analyzing proteins and peptides. Trends Biochem Sci 2001; 26: 687-689.

23 Pendleton N, Dixon GR, Green JA, Myskow MW. Expression of markers of differentiation in normal bronchial epithelium and bronchical dysplasia. J Pathol 1996; 178: 146-150.

24 Gianazza E, Allegra L, Bucchioni E, et al. Increased keratin content detected by proteomic analysis of exhaled breath condensate from healthy persons who smoke. Am J Med 2004; 117: 51-54.

25 Jackson AS, Sandrini A, Campbell C, Chow S, Thomas PS, Yates DH. Comparison of biomarkers in exhaled breath condensate and bronchoalveolar lavage. Am J Respir Crit Care Med 2007; 175: 222-227. 